Trauma Surgery \& Acute Care Open

\section{Predictors of hospitalization and surgical intervention among patients with motorcycle injuries}

\author{
Cary Fletcher, ${ }^{\oplus 1}$ Derrick Mcdowell, ${ }^{1}$ Camelia Thompson, ${ }^{2}$ Kenneth James ${ }^{2}$
}

\begin{abstract}
'Orthopaedics, St Ann's Bay Regional Hospital, St Ann, Jamaica

${ }^{2}$ Community Health and Psychaitry, University of the West Indies, Mona, Saint Andrew, Jamaica
\end{abstract}

Correspondence to Dr Cary Fletcher, St Ann's Bay Regional Hospital, St Ann JMCAN10, Jamaica; c.fletch30@ yahoo.com

Received 19 April 2019 Revised 25 July 2019 Accepted 30 July 2019
(C) Author(s) (or their employer(s)) 2019. Re-use permitted under CC BY-NC. No commercial re-use. See rights and permissions. Published by BMJ.

To cite: Fletcher $C$ Mcdowell D, Thompson C, et al. Trauma Surg Acute Care Open 2019:4:e000326.

\section{ABSTRACT}

Background To describe the distribution of injuries, hospitalization rates by body areas injured, and surgeryrequiring admissions, and to identify independent predictors of admission to a regional hospital in Jamaica. Methods A cross-sectional study was conducted among persons presenting to the St Ann's Bay Regional Hospital in Jamaica (2016-2018) with injuries sustained from motorcycle crashes. A census was done of patients admitted to the surgery ward from the emergency room, as well as those referred to the Orthopaedic Outpatient Department. Trained members of the orthopedic team administered a pretested questionnaire within 24 hours of presenting to the orthopedic service to elicit data on sociodemographic characteristics, motor vehicle collision circumstance and motor bike specifications, physical injuries sustained and medical management, as well as compliance with legal requirements for riding a motorcycle. Associations between variables were examined using $\chi^{2}$ tests and logistic regression.

Results There were 155 participants in the study, and $75.3 \%$ of motorcyclists with injuries required admission. The average length of stay was approximately 10 days. Surgery was required for $71.6 \%$ of those admitted. Lower limb injuries constituted $55 \%$ of all injuries. The independent predictors for admission were alcohol use and total body areas involved. Motorcycle crash victims who used alcohol close to the time of crash were three times more likely to be admitted to hospital than those who did not consume alcohol. As the total body areas involved increased by one, there was a threefold increase in the likelihood of being admitted. Additionally, the greater the number of body areas involved, the greater was the likelihood of admission.

Discussion Lower limb injuries are the most commonly reported injuries among victims of motorcycle crashes. Alcohol and total body areas involved are independent predictors of admission to hospital. In the planning of trauma delivery services, this information should be taken into account.

Level of Evidence Level IV.

\section{INTRODUCTION}

Motorcycle-related injuries continue to increase globally. ${ }^{1}$ These injuries are costly to individuals as well as society. ${ }^{2}$ Injuries, especially to the young, result in economic losses from premature mortality or associated cost of care. The sequelae of these injuries cause significant medical expenditure, loss of work time, and intangible suffering. ${ }^{3-6}$

In Jamaica, 2017 data indicate that among road traffic fatalities, the proportional mortality attributable to motorcycle crashes (drivers and pillion riders) was approximately $34 \% .^{7}$ None of these fatalities were 60 years or older. ${ }^{8}$ The number of motorcycle crashes in Jamaica has increased from 45 in 2012, to 105 in 2017, the motorcycle crash rate rising from 9.6 to 11.7 per 100000 population for the same period. ${ }^{9}$

Unlike other motor vehicles, motorcycles afford no external protection to the rider. Consequently a variety of injuries including musculoskeletal injuries commonly occur. Orthopedic injuries predominate among injuries after motorcycle crashes. ${ }^{10}{ }^{11}$ Lower limb injuries are preponderant, partly due to exposure or inadequate protection of the lower limbs, ${ }^{4} 12$ and in an early study inadequate footwear for the rider and pillion and rear wheel defects were cited..$^{13}$ Other common sites of injury are the upper limbs and the thorax..$^{1011}{ }^{14} \mathrm{Lin}$ et $a l^{15}$ in their prospective study found that severity of motorcycle injuries was more likely to increase when the collisions involve heavier vehicles and if the motor vehicle collision occurred in poor lighting. Severity has been linked to road conditions, ${ }^{16}{ }^{17}$ rurality, ${ }^{10}{ }^{16}$ older age, ${ }^{18}$ and speeding. ${ }^{15} 17$

Kasantikul et $a l^{19}$ in their motor vehicle collision scene study found that alcohol was the most important risk factor causing motorcycle crashes; $36 \%$ of the riders in their study were found to be under the influence of alcohol. They stated that motor vehicle collisions involving intoxicated riders more commonly occurred on weekends, especially at nights while the rider was on his way home; $33 \%$ of intoxicated riders required hospitalization, $25 \%$ did not go to hospital, and $42 \%$ were managed solely in the emergency room. Rifaat et $a l^{17}$ also found an association between alcohol use and injury severity from motorcycle collisions; alcohol impaired motorcyclists were approximately two to three times more likely to have severe injuries. ${ }^{17}$

Gorski et $a^{20}$ in their study of 270 riders involved in motor vehicle collisions reported a mean age of 26 years, and more than 99\% were male. Of the patients, $66 \%$ required admission and $36 \%$ required surgery. Their hospital stay ranged from 1 to 9 days. In another study, almost one in three patients required admission to the hospital (either to the ward or the intensive care unit). ${ }^{21}$ Fouda et $a l^{10}$ reported that surgical management for orthopedic injuries ensued in approximately $74 \%$ of injured motorcyclists admitted.

Motorcycles are the vehicle of choice for many road users due to their price and affordability, ease of navigation through traffic, and ability to traverse otherwise inaccessible areas. Little is known or documented on admission rates and subsequent need for surgical intervention among injured 
motorcyclists in Jamaica. Greater understanding of motorcycle injuries and hospital-associated consequences is thus warranted. This study describes the distribution of injuries, hospitalization rates by body areas injured, surgery-requiring admissions, and independent predictors of admission to a regional hospital in Jamaica. Hospitalization can serve as a proxy measure for severity of injury. ${ }^{22}$ Study findings can elucidate the burden of admissions and surgical implications and ultimately facilitate better planning in the health sector. Additionally the findings may help inform policies and strategies related to motorcycle collisions and injuries.

\section{METHODS}

During the period of March 2016 to June 2018, a cross-sectional study was conducted among persons presenting to St Ann's Bay Regional Hospital in Jamaica for injuries sustained from motorcycle crashes. The hospital is the main referral facility in the north-east region, consisting of the parishes of St Ann, St Mary, and Portland.

A census was done of patients presenting to hospital for injuries resulting from a motorcycle crash who were admitted to the surgery ward from the emergency room primarily for orthopedic injuries, as well as such patients referred to the Orthopaedic Outpatient Department. Orthopedic injuries in this study refer to injuries of the musculoskeletal system, often relating to the bones, muscles, joints, tendons, and ligaments. Trained members of the orthopedic team administered a pretested questionnaire within 24 hours of the patient presenting to the orthopedic service to obtain data on sociodemographic characteristics as well as crash circumstances. Clinical-related data were obtained from patient charts. Where neurologically contraindicated, interviews were deferred until deemed appropriate. The questionnaire elicited data on sociodemographic characteristics (age, gender employment status and parish of residence), crash circumstances (reported main activity leading to motorcycle crash, ie, loss of control and whether or not a collision occurred), and motor bike specifications (cubic centimeter rating - the volume of the internal combustion engine cylinders of motorcycles). Data on legal requirements for riding a motor bike (use of helmet, having a valid rider's license and motorcycle insurance) as well as alcohol use were collected. Alcohol use was deemed a history of consumption of alcoholic beverage 3 hours or less prior to the time of the crash and was self-reported. Information on physical injuries sustained and subsequent medical management was also obtained from patient charts.

Data were analyzed using SPSS V.20 and descriptive summaries generated. Bivariate analysis examined the associations between variables, and binary logistic regression was subsequently used to identify predictors of admission. Variables entered in the model were those with $\mathrm{p}$ values less than 0.1 in bivariate analyses (age, alcohol use, collision, loss of control and total number of body areas involved).

\section{RESULTS}

A total of 155 persons presented to the hospital with motorcycle injuries (116 required admission and 39 were referred to the orthopedic outpatient clinic). The majority (98.7\%) of study subjects were male. The median age was 28 years $(\mathrm{IQR}=16.5$ years). Persons in the 20 to 29 years age category constituted the largest $(47.1 \%)$ proportion of motorcycle injuries, followed by the 30 to 39 years age category (20.3\%), whereas those 40 to 49 years and 50 and older each constituted $12.4 \%$. The under-20 years category had the lowest $(7.8 \%)$ proportion of

\begin{tabular}{|c|c|c|c|c|c|}
\hline \multirow{2}{*}{$\begin{array}{l}\text { Body area } \\
\text { involved }\end{array}$} & \multirow{2}{*}{$\begin{array}{l}\text { Total } \\
\text { injured }\end{array}$} & \multicolumn{2}{|c|}{ Requiring admission } & \multicolumn{2}{|c|}{ Requiring surgery } \\
\hline & & $\mathrm{n}$ & $\%$ & $\mathrm{n}$ & $\%$ \\
\hline Hand & 16 & 9 & 56 & 6 & 38 \\
\hline Wrist & 10 & 10 & 100 & 5 & 50 \\
\hline Forearm & 24 & 19 & 79 & 12 & 50 \\
\hline Arm/Shoulder & 21 & 12 & 57 & 1 & 5 \\
\hline Foot & 17 & 11 & 65 & 8 & 47 \\
\hline Ankle & 24 & 17 & 71 & 15 & 63 \\
\hline Leg & 36 & 33 & 92 & 28 & 78 \\
\hline Knee & 11 & 9 & 82 & 7 & 64 \\
\hline Thigh & 23 & 21 & 91 & 21 & 91 \\
\hline Pelvis & 9 & 9 & 100 & 5 & 56 \\
\hline Spine & 10 & 10 & 100 & 0 & 0 \\
\hline
\end{tabular}

motorcycle injuries. Of the participants $63 \%$ lived in the parish of St Ann, 18.2\% in St Mary, and the remaining (18.8\%) in other parishes. Almost $88 \%$ of persons were employed, and at the time of the motorcycle crash $91 \%$ were riders and $9 \%$ pillion riders.

\section{Description of injuries}

Injury was specified for $98.7 \%$ of the 155 persons who participated in the study. Lower limb accounted for 55\% of injuries, whereas $35 \%$ and $10 \%$ of injuries occurred in the upper limb and the pelvis/spine, respectively. In the lower limb, leg, ankle, and thigh injuries were most common, whereas forearm and shoulder injuries were predominant in the upper limbs.

\section{Admissions and surgeries for motorcycle injuries}

Among motorcyclists presenting to hospital with injuries, $75.3 \%$ $(n=116)$ required admission. The duration of stay ranged from 1 to 89 days. The plurality (49.6\%) were admitted for less than 1 week, $30.4 \%$ were admitted for 1 to 2 weeks, and $20 \%$ greater than 2 weeks. The average length of stay was approximately 10 days $(\mathrm{SD}=8)$. Surgery was required for $71.6 \%(n=83)$ of those admitted. As seen in table 1 , the majority, identified with a particular body part injury, required admission (due to either significant injury to that body part or associated concomitant injury). All motorcyclists with injuries to the pelvis and spine required admission. Surgeries were predominantly done for lower limb injuries, with the surgery to the thigh and legs accounting for the largest proportion of body part injuries requiring surgery.

Tables 2 and 3 outline admission and surgery disaggregated by sociodemographic characteristics, body areas involved, main mechanism of injury (loss of control or collision), motorcycle characteristics, and compliance with legal operations for operating a motorcycle. Statistically significant associations were found with admission and alcohol use, total body areas involved, and the mechanisms of injury (loss of control and collision). Almost $84 \%$ of those who consumed alcohol close to the time of the motorcycle crash were admitted to hospital, compared with $68.5 \%$ of those who did not consume alcohol. As the total number of body areas involved increased, generally the proportion requiring admission increased. Where loss of control was the main mechanism involved in the injury, $85.2 \%$ of motorcyclists required admission. Among motorcyclists with collision as the main mechanism of injury, $70.3 \%$ of them required admission. A statistically significant association was also noted between total body areas involved and requirement for surgery. 
Table 2 Admission disaggregated by select variables

\begin{tabular}{|c|c|c|c|}
\hline \multirow[b]{2}{*}{ Variables } & \multicolumn{3}{|c|}{ Admission, $\mathrm{n}(\%)$} \\
\hline & Yes & No & $\chi^{2}, p$ value \\
\hline \multicolumn{4}{|l|}{ Gender ( $n=154)$} \\
\hline Male & $114(75.0)$ & $38(25.0)$ & 0.415 \\
\hline Female & $2(100.0)$ & $0(0.0)$ & \\
\hline \multicolumn{4}{|c|}{ Age category $(n=153)$ (years) } \\
\hline Under 20 & $8(66.7)$ & $4(33.3)$ & \\
\hline $20-29$ & $55(76.4)$ & $17(23.6)$ & \\
\hline $30-39$ & $26(83.9)$ & $5(16.1)$ & $0.067^{*}$ \\
\hline $40-49$ & $17(89.5)$ & $2(10.5)$ & \\
\hline 50 and over & $10(52.6)$ & $9(47.4)$ & \\
\hline \multicolumn{4}{|c|}{ Employment $(n=153)$} \\
\hline Yes & $102(76.1)$ & $32(23.9)$ & 0.467 \\
\hline No & $13(68.4)$ & $6(31.6)$ & \\
\hline \multicolumn{4}{|c|}{ Alcohol use $(n=151)$} \\
\hline Yes & $52(83.9)$ & $10(16.1)$ & $0.033 \dagger$ \\
\hline No & $61(68.5)$ & $28(31.5)$ & \\
\hline \multicolumn{4}{|c|}{ Total body areas involved $(n=154)$} \\
\hline 1 & $77(69.4)$ & $34(30.6)$ & \\
\hline 2 & $29(93.5)$ & $2(6.5)$ & \\
\hline 3 & $7(77.8)$ & $2(22.2)$ & $0.034^{*}$ \\
\hline 4 & $2(100.0)$ & $0(0.0)$ & \\
\hline 5 & $1(100.0)$ & $0(0.0)$ & \\
\hline \multicolumn{4}{|c|}{ Loss of control $(n=148)$} \\
\hline Yes & $69(85.2)$ & $12(14.8)$ & $0.003+$ \\
\hline No & $43(64.2)$ & $24(35.8)$ & \\
\hline \multicolumn{4}{|l|}{ Collision ( $n=148)$} \\
\hline Yes & $71(70.3)$ & $30(29.7)$ & $0.025 t$ \\
\hline No & $41(87.2)$ & $6(12.8)$ & \\
\hline \multicolumn{4}{|l|}{ cc rating $(\mathrm{n}=149)$} \\
\hline $150 \mathrm{cc}$ and less & $71(73.2)$ & $26(26.8)$ & 0.303 \\
\hline $\begin{array}{l}\text { Greater than } \\
150 \mathrm{cc}\end{array}$ & $42(80.8)$ & $10(19.2)$ & \\
\hline \multicolumn{4}{|l|}{ Insurance ( $n=141)$} \\
\hline Yes & $24(68.6)$ & $11(31.4)$ & 0.196 \\
\hline No & $84(79.2)$ & $22(20.8)$ & \\
\hline \multicolumn{4}{|c|}{ Rider's license $(n=141)$} \\
\hline Yes & $27(73.0)$ & $10(27.0)$ & 0.545 \\
\hline No & $81(77.9)$ & $23(22.1)$ & \\
\hline \multicolumn{4}{|c|}{ Helmet use ( $n=153$ ) } \\
\hline Yes & $32(71.1)$ & $13(28.9)$ & 0.454 \\
\hline No & $83(76.9)$ & $25(23.1)$ & \\
\hline
\end{tabular}

* $P$ value based on Fisher's exact test.

tDenotes statistical significance at the 0.05 alpha level.

$\mathrm{cc}$, cubic centimeter (represents the volume of the internal combustion engine cylinders of motorcycles).

The proportion of persons requiring surgery increased as the cumulative number of body parts involved increased.

\section{Independent predictors of admission}

A binary logistic regression model developed identified significant predictors of admission to hospital among motorcyclists with injuries sustained from motorcycle crashes (table 4). Variables entered in the model were those with $\mathrm{p}$ values less than 0.1 in bivariate analyses (age, alcohol use, collision, loss of
Table 3 Surgery disaggregated by select variables

\begin{tabular}{|c|c|c|c|}
\hline \multirow[b]{2}{*}{ Variables } & \multicolumn{3}{|c|}{ Surgery, n (\%) } \\
\hline & Yes & No & $\chi^{2}, p$ value \\
\hline \multicolumn{4}{|l|}{ Gender $(n=155)$} \\
\hline Male & $91(59.5)$ & $62(40.5)$ & 0.245 \\
\hline Female & $2(100.0)$ & $0(0.0)$ & \\
\hline \multicolumn{4}{|c|}{ Age category $(n=153)$ (years) } \\
\hline Under 20 & $10(83.3)$ & $2(16.7)$ & \\
\hline $20-29$ & $46(63.9)$ & $26(36.1)$ & \\
\hline 30-39 & $18(58.1)$ & $13(41.9)$ & 0.218 \\
\hline $40-49$ & $9(47.4)$ & $10(52.6)$ & \\
\hline 50 and over & $9(47.4)$ & $10(52.6)$ & \\
\hline \multicolumn{4}{|l|}{ Employment ( $n=154)$} \\
\hline Yes & $78(57.8)$ & $57(42.2)$ & 0.186 \\
\hline No & $14(73.7)$ & $5(23.3)$ & \\
\hline \multicolumn{4}{|l|}{ Alcohol use $(n=151)$} \\
\hline Yes & $37(59.7)$ & $25(40.3)$ & 0.878 \\
\hline No & $52(58.4)$ & $37(41.6)$ & \\
\hline \multicolumn{4}{|c|}{ Total body areas involved $(n=154)$} \\
\hline 1 & $60(54.1)$ & $51(45.9)$ & \\
\hline 2 & $25(80.6)$ & $6(19.4)$ & \\
\hline 3 & $4(44.4)$ & $5(55.6)$ & $0.019^{*}$ \\
\hline 4 & $2(100.0)$ & $0(0.0)$ & \\
\hline 5 & $1(100.0)$ & $0(0.0)$ & \\
\hline \multicolumn{4}{|l|}{ Loss of control $(n=148)$} \\
\hline Yes & $51(63.0)$ & $30(37.0)$ & 0.44 \\
\hline No & $38(56.7)$ & $29(43.3)$ & \\
\hline \multicolumn{4}{|l|}{ Collision ( $n=148)$} \\
\hline Yes & $62(61.4)$ & 39 (38.6) & 0.649 \\
\hline No & $27(57.4)$ & $20(42.6)$ & \\
\hline \multicolumn{4}{|l|}{ cc rating ( $n=149)$} \\
\hline $150 \mathrm{cc}$ and less & $56(57.7)$ & $41(42.3)$ & 0.363 \\
\hline Greater than $150 \mathrm{cc}$ & $34(65.4)$ & 18 (34.6) & \\
\hline \multicolumn{4}{|l|}{ Insurance $(n=141)$} \\
\hline Yes & $18(51.4)$ & 17 (48.6) & 0.257 \\
\hline No & $66(62.3)$ & $40(37.7)$ & \\
\hline \multicolumn{4}{|l|}{ Rider's license ( $n=141)$} \\
\hline Yes & $20(54.1)$ & $17(45.9)$ & 0.426 \\
\hline No & $64(61.5)$ & $40(38.5)$ & \\
\hline \multicolumn{4}{|l|}{ Helmet use ( $n=153$ ) } \\
\hline Yes & $25(55.6)$ & $20(44.4)$ & 0.524 \\
\hline No & $66(61.1)$ & $42(38.9)$ & \\
\hline
\end{tabular}

${ }^{*} P$ value based on Fisher's exact test.

$c c$, cubic centimeter (represents the volume of the internal combustion engine cylinders of motorcycles).

control, and total number of body areas involved). The significant predictors for admission were alcohol use and total body areas involved. Motorcycle crash victims who used alcohol close to the time of crash were three times more likely to be admitted than those who did not consume alcohol. As the total body areas involved increased by one, there was a threefold increase in the likelihood of being admitted.

\section{DISCUSSION}

Studies involving trauma epidemiology serve to document critical information pertaining to mortality, morbidity, and 


\begin{tabular}{|c|c|c|}
\hline Variables & OR $(95 \% \mathrm{Cl})$ & $P$ value \\
\hline \multicolumn{3}{|l|}{ Alcohol } \\
\hline No & Reference & \\
\hline Yes & $3.00(1.17 \text { to } 7.74)^{*}$ & 0.023 \\
\hline \multicolumn{3}{|c|}{ Mechanism of injury (collision) } \\
\hline No & Reference & \\
\hline Yes & 0.57 (0.16 to 2.01$)$ & 0.396 \\
\hline \multicolumn{3}{|c|}{ Mechanism of injury (loss of control) } \\
\hline No & Reference & \\
\hline Yes & $2.73(0.93$ to 8.03$)$ & 0.069 \\
\hline $\begin{array}{l}\text { Total number of body areas } \\
\text { involved }\end{array}$ & $3.03(1.01 \text { to } 9.11)^{*}$ & 0.049 \\
\hline \multicolumn{3}{|l|}{ Age category (years) } \\
\hline Under 20 & Reference & - \\
\hline $20-29$ & $1.05(0.26$ to 4.29$)$ & 0.944 \\
\hline $30-39$ & $1.94(0.38$ to 9.79$)$ & 0.423 \\
\hline $40-49$ & 2.89 (0.38 to 21.71$)$ & 0.309 \\
\hline 50 and over & $0.31(0.06$ to 1.64$)$ & 0.167 \\
\hline
\end{tabular}

*Denotes statistical significance at the 0.05 alpha level.

disability. Consistent with other studies, our findings confirmed the predominance of lower limb injuries among injured motorcyclists. ${ }^{411}$ In our study, lower limb injuries had relatively high rates of admission and surgical intervention. This observation warrants consideration in the planning of trauma service delivery, particularly with respect to adequate human resources, bed capacity, and equipment and supplies. Measures to prevent lower limb injury such as wearing protective boots, kneepads, and padded gears should be encouraged. One public health measure to reduce such injuries is increased commercial access and availability of these protective items by reducing or waiving associated consumption taxes.

Hospitalization, a consequence of motorcycle injuries, can be financially burdensome especially where there is prolonged stay. In our study, the average length of stay was approximately 10 days and comparatively lower than 18.3 and 19.2 days reported from Tanzania and Brazil. ${ }^{23}{ }^{24}$ These differences may be due to variations in case severity and availability of technology, operating theater time and staff, and bed capacity/occupancy.

Alcohol use was found to be an independently associated factor for admission. There was a threefold increased probability of being admitted among those who had used alcohol close to the time of motor vehicle collision. Our results are consistent with that of Rifaat et al, ${ }^{17}$ who found a 2.7 to 3.2 times greater risk of injury when alcohol was involved. Our findings underscore the importance of refraining from alcohol use when operating motorcycles and its importance in reducing injury should a motor vehicle collision occur.

The total number of body areas involved likely reflects the injury impact; therefore, its association with admission and surgery is not surprising. More injuries incur greater costs and resource use. There is an imperative to reduce injury, through reduction in speeding, better road conditions, law enforcement initiatives, and use of protective gear.

Our study is the first to examine admission and surgical intervention rates for motorcycle injuries in Jamaica. The study allowed for real-time data collection. In our setting we have added to the body of knowledge by revealing alcohol use as an important determinant of admission to hospital.
We acknowledged the limitations of our study. Alcohol use was self-reported and not objectively verified. The study was also confined to one health region and the results are not necessarily generalizable to the wider national population. Injuries by body part are reported as isolated injuries primarily to illustrate the distribution of injuries. However, decisions around admissions and subsequent operations are likely a function of combinations of injuries. Future work may explore this further.

\section{CONCLUSION}

Lower limb injuries are the most commonly reported injuries among victims of motorcycle crashes. Alcohol and total body areas involved are independent predictors of admission to hospital. The information regarding admission and surgical interventions should be taken into account to ensure relevance, adequacy, and responsiveness of trauma delivery services. Sanctions relating to alcohol use while riding motorcycles should be more rigorously enforced. Greater use of protective gear including lower limb protection should be advocated.

Contributors CF conceptualized the study, participated in study design and data collection, performed statistical analyses, and contributed to article writing. DM participated in study design, and contributed to article writing and revision. CT performed statistical analyses, and contributed to article writing and revision. $\mathrm{KJ}$ performed statistical analyses and contributed to article writing. All authors approved the final version.

Funding The authors have not declared a specific grant for this research from any funding agency in the public, commercial or not-for-profit sectors.

Competing interests None declared.

Patient consent for publication Not required.

Ethics approval Informed consent was obtained from all participants in the study, and authorization was obtained from the hospital to conduct the study.

Provenance and peer review Not commissioned; externally peer reviewed.

Data availability statement There are no data in this work. All data relevant to the study are included in the article. No data are available.

Open access This is an open access article distributed in accordance with the Creative Commons Attribution Non Commercial (CC BY-NC 4.0) license, which permits others to distribute, remix, adapt, build upon this work non-commercially, and license their derivative works on different terms, provided the original work is properly cited, appropriate credit is given, any changes made indicated, and the use is non-commercial. See: http://creativecommons.org/licenses/by-nc/4.0/.

\section{REFERENCES}

1. World Health Organization. Global status report on road safety 2018 [Internet]. 2018 https://www.who.int/violence_injury prevention/road_safety status/2018/EnglishSummary-GSRRS2018.pdf.

2. Kudebong M, Wurapa F, Nonvignon J, Norman I, Awoonor-Williams JK, Aikins M. Economic burden of motorcycle accidents in northern Ghana. Ghana Med J 2011;45:135-42.

3. Pincus D, Wasserstein D, Nathens AB, Bai YQ, Redelmeier DA, Wodchis WP. Direct medical costs of motorcycle crashes in Ontario. Can Med Assoc J 2017;189:E141 0-E1415.

4. Miki N, Martimbianco ALC, Hira LT, Lahoz GL, Fernandes HJA, Reis FBdos. Profile of trauma victims of motorcycle accidents treated at hospital São Paulo. Acta Ortop Bras 2014;22:219-22

5. Debieux P, Chertman C, Mansur NSB, Dobashi E, Fernandes HJA. Musculoskeletal injuries in motorcycle accidents. Haseki Tip Bul 2015;18:353-6.

6. Dos Anjos KC, de Rezende MR, Mattar R. Social and hospital costs of patients admitted to a university hospital in Brazil due to motorcycle crashes. Traffic Inj Prev 2017; 18:585-92.

7. National Road Safety Council. Road Crash Fatalities by Category 2002 - 2017 [Internet]. 2018. http://www.nationalroadsafetycouncil.org.jm/pdf/Crash-Stats-byCategory-2002-2017.pdf.

8. Ministry of Transport and Mining. Traffic Crash Report [Internet]. 2017. http://www. mtw.gov.jm/roadsafety/images/Reports_And_Statistics/Weekly/2017/March/Crash_ Report_March_16_2017.pdf.

9. National Road Safety Council. Road Fatalities/100,000 Population 1991-2017 [Internet]. 2017. http://www.nationalroadsafetycouncil.org.jm/pdf/Motor-VehicleCrash-Fatalities-1991-2017.pdf. 
10. Fouda EY, Youssef M, Emile SH, Elfeki H, Thabet W, Abdallah E, Elshobaky A, Toma MS, Khafagy W, et al. Pattern of major injuries after motorcycle accidents in Egypt: the Mansoura emergency Hospital experience. Trauma 2017;19:39-45.

11. Cavalcanti AL, Lucena BM, Rodrigues ISA, Silva AL, Lima TT, Xavier AFC. Motorcycle accidents: morbidity and associated factors in a city of northeast of Brazil. Tanzan J Health Res 2013;15:209-15.

12. Hui Z, Wei H, Guang-yu Y, Rong C, Sheng-xiong L, Yong-min Y, et al. Analysis of 86 fatal motorcycle frontal crashes in Chongqing, China. Chin J Traumatol 2012;15:170-4.

13. Wong TW, Phoon WO, Lee J, Yiu PC, Fung KP, Smith G, McLean AJ. Non-Fatal injuries among motorcyclists treated as in-patients in a general Hospital. Ann Acad Med Singapore 1989;18:672-4.

14. Crandon IW, Harding HE, Cawich SO, MCDonald AH, Fearron-Boothe D. Motorcycle accident injury profiles in Jamaica: an audit from the university hospital of the West Indies. Int J Inj Contr Saf Promot 2009;16:175-8.

15. Lin M-R, Chang S-H, Huang W, Hwang H-F, Pai L. Factors associated with severity of motorcycle injuries among young adult riders. Ann Emerg Med 2003:41:783-91.

16. Chang F, Li M, Xu P, Zhou H, Haque M, Huang H. Injury severity of motorcycle riders involved in traffic crashes in Hunan, China: a mixed ordered logit approach. Int J Environ Res Public Health 2016;13:714
17. Rifaat SM, Tay R, de Barros A. Severity of motorcycle crashes in Calgary. Accid Anal Prev 2012;49:44-9.

18. Cunto FJC, Ferreira S. An analysis of the injury severity of motorcycle crashes in Brazil using mixed ordered response models. I Transp Saf Secur 2017;9(Suppl 1):33-46.

19. Kasantikul V, Ouellet JV, Smith T, Sirathranont J, Panichabhongse V. The role of alcohol in Thailand motorcycle crashes. Accid Anal Prev 2005;37:357-66.

20. Gorski TF, Gorski YC, McLeod G, Suh D, Cordero R, Essien F, Berry D, Dada F. Patterns of injury and outcomes associated with Motocross accidents. Am Surg 2003;69:895-8.

21. Abdul-Sahib M, Al-Ghabban SI. Lower limb injuries associated with motorcycle accidents in Holy Karbala City in Iraq. Research 2014;1:678.

22. Sears JM, Bowman SM, Rotert M, Hogg-Johnson S. A new method to classify injury severity by diagnosis: validation using workers' compensation and trauma registry data. J Occup Rehabil 2015;25:742-51.

23. Chalya PL, Mabula JB, Ngayomela IH, Kanumba ES, Chandika AB, Giiti G, Mawala B, Balumuka DD. Motorcycle injuries as an emerging public health problem in Mwanza City, north-western Tanzania. Tanzan J Health Res 2010;12:214-21.

24. de Araujo GL, Whitaker YI. Hospital morbidity of injured motorcyclists: factors associated with length of stay. Acta Paul Enferm 2016;29:178-84. 